www.nature.com/pj

\title{
EDITORIAL
}

\section{SPSJ Award for the outstanding papers in Polymer Journal 2009 sponsored by ZEON}

Polymer Journal (2010) 42, 423-424; doi:10.1038/pj.2010.36

$\mathrm{T}$

The Society of Polymer Science Japan (SPSJ) has announced 1 the winners of the 2009 PJ ZEON Award. Each year, three young authors of the outstanding papers published in Polymer Journal are selected for the PJ ZEON Award by the selection committee and board of directors of SPSJ. For 2009, the winners are:

Dr Tomoaki Matsugi (Research Center, Mitsui Chemicals Inc.) for the contribution of 'Surface Modification of Polypropylene Molded Sheets by Means of Surface-Initiated ATRP of Methacrylates' Vol. 41, No. 7, 2009.

Dr Noriyoshi Matsumi (Graduate School of Bioagricultural Sciences, Nagoya University) for the contribution of 'Enhanced Ionic Conduction in Organoboron Ion Gels Facilely Designed via Condensation of Cellulose with Boric Acids in Ionic Liquids' Vol. 41, No. 5, 2009.

Dr Ken Terao (Graduate School of Science, Osaka University) for the contribution of 'Solution Properties of Amylose Tris(Phenylcarbamate): Local Conformation and Chain Stiffness in 1,4-Dioxane and 2-Ethoxyethanol Vol. 41, No. 3, 2009.

Details of the winners follow this announcement.

Dr Matsugi, Dr Matsumi and Dr Terao were invited to receive the award diploma and a medal at the award ceremony held in conjunction with SPSJ annual meeting in May 2010 in Yokohama. Prize money of 300000 yen was also offered to each winner and they were invited to give a talk based on the award paper.

On behalf of the Polymer Journal and the journal's editorial board, I congratulate Dr Matsugi, Dr Matsumi and Dr Terao on their well-deserved honor, and their excellent papers. I hope the award will provide good encouragement to these young researchers and lead them to further success.

The Award is open to all Polymer Journal first authors who were under 38 years old at the time of submission. I hope this award will help drive submissions from eligible authors to Polymer Journal, and look forward to seeing many applications for the 2010 PJ ZEON Award. Those interested should go to SPSJ's website (http:// www.spsj.or.jp) for further information. Finally, let me acknowledge our sincere appreciation to Zeon Corporation for their generous sponsorship of this Award.

Toshikazu Takata Editor-in-Chief

\section{ABOUT THE WINNERS}

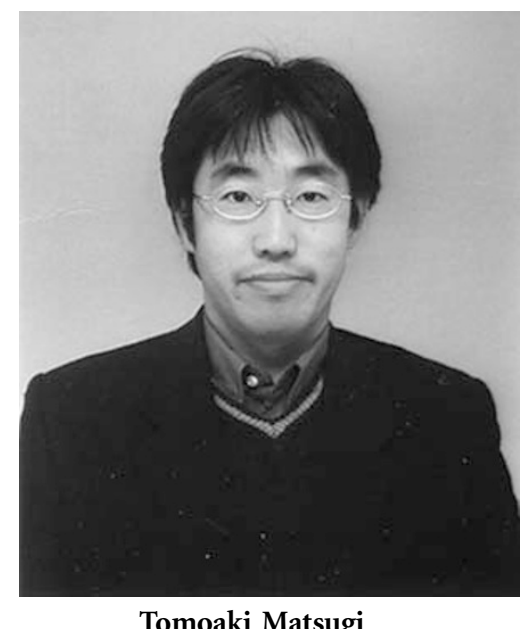

Dr Matsugi graduated from Kyushu University with an MS degree in chemistry in 1997, working under Professor Seiji Shinkai and Itaru Hamachi. He joined Mitsui Petrochemical Industries Ltd (now Mitsui Chemicals Inc.) in 1997. He received his $\mathrm{PhD}$ degree in chemistry from Kyushu University in 2008. His research interests include the development of olefin polymerization catalysts and valuable polyolefin-based materials.

About the award article: The authors investigated the surfaceinitiated ATRP of two kinds of methacrylate monomers on the surface of structurally well-defined polypropylene (PP)-macroinitiator molded sheets. It was clearly revealed that a high graft density poly(methyl methacrylate) brush was formed as a thin layer on the sheet surface. Abrasion characteristics of the poly(methyl methacrylate)-grafted PP sheet were compared with that of a poly(methyl methacrylate)-coated PP sheet using the dynamic friction test, in which a sliding stainless ball probe revealed higher wear resistance for the poly(methyl methacrylate)-grafted PP sheet. Wettability and antibacterial properties of the PP sheet surface were revealed to improve drastically as a result of the surface-initiated ATRP of MTAC. 


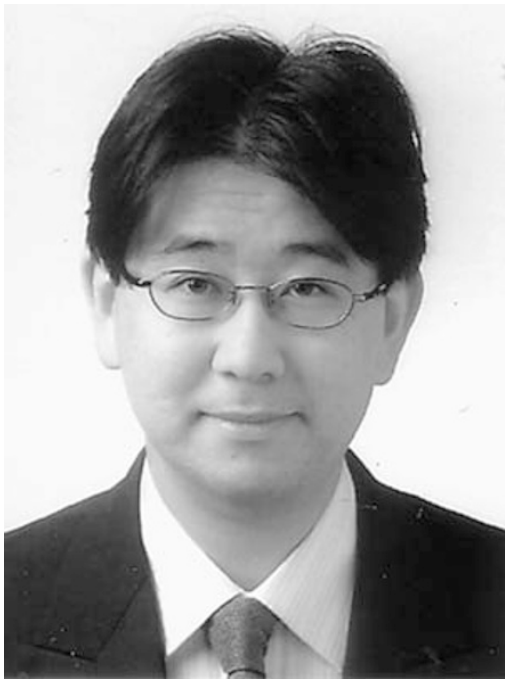

Noriyoshi Matsumi

Dr Matsumi received a BS degree from Kyoto University in 1995 and obtained Dr of engineering in polymer chemistry from the Graduate School of Engineering, Kyoto University in 2000 under the guidance by Professor Yoshiki Chujo. During 1999-2000, he received a Japan Society for Promotion of Science (JSPS) fellowship for research on creation of $\pi$-conjugated organoboron polymers. He then became assistant professor at Tokyo University of Agriculture and Technology, working with Professor Hiroyuki Ohno. Therein, he studied selective cation transport in organoboron polymer electrolytes and organoboron ionic liquids. He also developed various single ion conductive organoboron polymer/salt hybrid materials including dissociable lithium salt. In 2006, he joined the Graduate School of Bioagricultural Sciences, Nagoya University as associate professor. He received the award for encouragement of research in polymer science from SPSJ in 2006. At present, he is performing the design of nonflammable organic-inorganic hybrid type ion-gels as electrolytes for Li-ion batteries with the aid of NEDO. His current research interest is organoboron functional materials, polymer electrolytes, ionic liquids, bio-sensors based on $\pi$-conjugated materials and bio-based polymers.

About the award article: In the present work, novel ion gels bearing highly dissociable lithium pentafluorophenylborate were facilely synthesized by condensation between cellulose and boric acids in IL. The ion gels obtained can be regarded as a new class of organicinorganic polymer hybrid materials that are prepared only during several hours. Their ionic conductivities were evaluated by ac-impedance method after drying ion gels thoroughly. Ion gels obtained showed high ionic conductivity comparable to IL itself. The effect of concentration of $\mathrm{C}_{6} \mathrm{~F}_{5} \mathrm{~B}(\mathrm{OH})_{2}$ on ionic conductivity was examined with varying the ratio of $\mathrm{B}(\mathrm{OH})_{3}$ and $\mathrm{C}_{6} \mathrm{~F}_{5} \mathrm{~B}(\mathrm{OH})_{2}$. The ion gel including greater amount of pentafluorophenylborate showed significantly enhanced ionic conductivity.

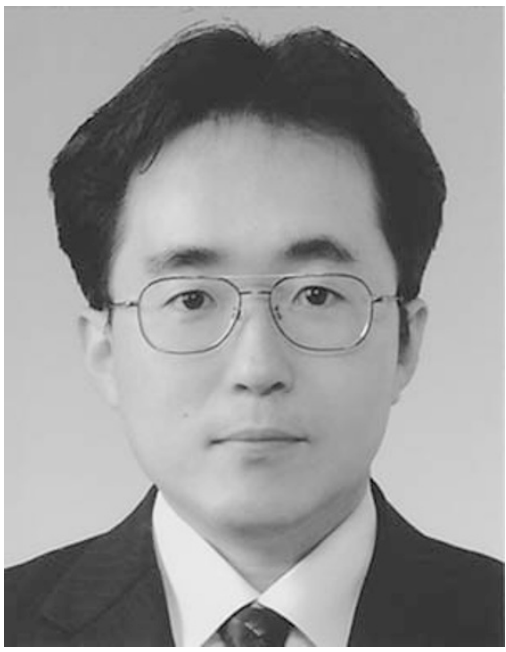

Ken Terao

Dr Terao, born in 1971 (Osaka, Japan), received his BS in 1994 and PhD in 1999 (Osaka University). He worked at Ritsumeikan University as a researcher from 1999 to 2001 and at Gunma University as an assistant professor from 2001 to 2005 . He joined Osaka University in 2005 as an assistant professor. His current research interests include solution properties of helical polysaccharide derivatives, collagen model peptides and conjugated polyelectrolytes.

About the award article: The authors analyzed solution data of amylose tris(phenylcarbamate) in terms of the wormlike chain model and determined the Kuhn segment lengths to be 22 and $16 \mathrm{~nm}$ in 1,4dioxane and 2-ethoxyethanol, respectively, and a contour length per residue to be $0.33 \mathrm{~nm}$ in both. They found that the polymer in solution has high stiffness and a contour length slightly shorter than the known value $0.37-0.40 \mathrm{~nm}$ for amylosetriesters in the crystalline state. These results are consistent with the intramolecular hydrogen bonding between the $\mathrm{C}=\mathrm{O}$ and $\mathrm{NH}$ groups of the neighbor repeating units detected by infrared absorption. 